\title{
Network assemblage of regime stability and resilience: comparing Europe and China
}

\author{
HILTON L. ROOT* \\ Schar School of Policy and Government, George Mason University, Arlington, VA, USA
}

\begin{abstract}
This article demonstrates that the network structures of historical regimes influence the way information is spread, which in turn circumscribe the behaviors of the different groups that make up the system. It advances two central claims. The first is a methodological one showing that patterns of long-term historical change are best studied at the system level, rather than by a traditional equilibrium framework grounded in models of individual behavior. Then, an empirical claim is established by comparisons of China's hub-and-spoke hypernetwork with Europe's multi-hub hypernetwork to show that their different patterns of interconnectivity forged their respective capacities to weather intermittent socioeconomic transitions.
\end{abstract}

\section{Introduction: the remarkable longevity of dynastic lordship in China and Europe}

It is axiomatic in comparative history that Europe's decentralized and competitive state system is the key to its developmental divergence from China. This paper references advances in network theory to show why it is not enough to say that Europe's dynamism stems from its decentralized political competition. Interstate rivalries and war also feature significantly across China's geopolitical landscape. However, political competition there produced severe periods of disruption and collapse without parallel in Europe (Andrade, 2016: 4-10).

The historical regimes in both China and Europe (and, in fact, all historical regimes) are multiscale systems in which different orders of hierarchy exist and intermingle, giving rise to change processes across levels. The interactions and co-evolution of these multilevel environments form the system's hypernetworks and produce system-level dynamics, as well. In this paper, we look at two very different hypernetwork structures in China and Europe, both of which evolved around the institution of hereditary dynastic succession. ${ }^{1}$ Both China

\footnotetext{
*Email: Hroot2@gmu.edu

1 China is considered as the world's longest continuous political system. Europe evolved into a mosaic of nation states, variegated in terms of people, culture, language, and history. As a social, economic, and cultural system, Europe comprises more or less independent parts-subsystems expressed in distinct
} 
and Europe-unlike other known historical meta-regimes, such as the Roman, Ottoman, or Mughal empires-established rule-based systems for clear, orderly, and incontestable lines of hereditary dynastic succession, and from the 9th century onward, their historical regimes were able to exhibit remarkable relative longevity. Dynastic lordship was a key institutional determinant for this constancy in both China and Europe and underlies what historian Vivek Swaroop Sharma calls the 'nature of authority in the society as a whole' (Sharma, 2015: 157).

The rules of succession afforded great longevity, a millennium in fact, to both regimes, but we will show that their different hypernetwork structures resulted in differences in the system-level properties of stability and resilience, and played major roles in the state development of each. ${ }^{2}$

Only recently have scholars of institutional change and economic development come to recognize that the central questions of how social institutions emerge, adapt, and evolve echo debates long occurring in the natural sciences, in fields as diverse as neurology, ecology, and physics, where it is understood that ecosystems are complex adaptive systems. Social scientists are now starting to apply this understanding to the connections between a system's microscopic and macroscopic components.

Families, clans, dynasties, and social institutions, such as markets, political parties, or the state itself, are all complex adaptive systems. Thus, a state is a nested hierarchy of intermingling components organized into levels, just as groups of individuals form families, groups of families form neighborhoods, groups of neighborhoods form cities, groups of cities form metropolitan regions, and so on. There is no real distinction between a component and the system it inhabits; and just as one system is the aggregate of its components, it is also an interactive agent of a yet larger system of self-organization. The agents at one level contribute to the behavior of the next, but at each level of aggregation, the behavior of the whole also shifts. Yet, no aggregate level exhibits the identical behavioral characteristics of its individual components.

languages, traditions, and conventions. Yet, its historical sources of unity are significant. Because its subsystems constantly and actively interact with one another, it is reasonable to consider Europe itself as a macro-system. Most important, it enjoyed the continuity of a common system of intermarried dynasties, which is the focus of this paper. It endowed Europe with characteristics of what Herbert Simon calls a 'nearly decomposable' system (Simon, 1962), one in which the short-term behavior each component is approximately independent of the short-term behaviors of any of the other components; yet, over the long term, the behavior of any component depends in an aggregate way upon the behaviors of all the other components. Thus, Europe as a collectivity—not any single country within Europe-is the appropriate unit of comparison.

2 A hypernetwork then is the shared element among the levels of a system; its structure can be a huband-spoke or starlike, or be entirely decentralized without any return to scale. As a multiscale system, a social system can have multiple hypernetworks, but this study concentrates on one: the structural dynamics created by dynastic succession among royal houses. The papacy is another parallel hypernetwork. 
Systems of networks form hypernetworks, the structures of which enable us to identify relationships within multilevel systems that account for longterm institutional stationarity, and to see more clearly answers to the following questions:

(1) Why did Europe emerge as a system that is more than the sum of its parts, despite its many diverse components evolving separately?

(2) Why was the Great War unavoidable in Europe, notwithstanding the degree of intermarriage among the royal houses?

(3) How can events in one local network cause a sequence of clustering transitions across the larger system, e.g., the Renaissance, which began in the Italian city states; the Reformation in a small German principality; and the French Revolution and the subsequent spread of nationalism?

(4) Why do durable regime transitions occur during periods of intermittent hyperactivity followed by long periods of stasis-such as the resurgence of conservatism in France after the worker rebellions of 1848 were crushed?

(5) Why do intervals of prolonged, intense warfare and extreme disorder, frequently lasting generations, occur between dynastic transitions in China?

(6) Why might a network structure become maladaptive over the long term, despite the properties of either stability or resilience?

\section{Institutions and equilibrium in political economy analysis}

The central methodological claim of this paper is that the micro-level equilibria within a social system rarely approximate the long-term behavior of the larger system, and that the larger system is formed by interactions and communications of many self-adjusting agents. Continuous 'feedback' motivates the agents to re-evaluate their positions; and because they constantly react to other agents' behaviors, nothing in the environment is fixed or finite. In order to understand the impacts of these agents, their behaviors must be understood as they interact within and with the broader system.

In this regard, social systems do not differ from other complex systems. Despite significant turmoil and variability at the micro-levels, notes Axtell (2014), complex systems frequently display long-term stationarity and can exhibit aggregate steady states. ${ }^{3}$ Thus, it is impossible to deduce a general theory of

3 Axtell discusses social processes where 'perpetual adaptation, co-evolution, and strategic adjustments are observed at the agent-level, whereas steady states were obtained at the macro-level' (Axtell, 2014: 1). Agent computing at full scale of the privately invested US economy, which employs 120 million workers, enables Axtell (Forthcoming) to observe stationary distributions at the aggregate level, despite continuous adaptation at agent levels. He finds continuous agent-level fluctuation, as millions of job seekers change employment in every period and new firms enter the market. Yet, the distribution of firm size and the scale of labor flows appear to be constant over time. The survival probability of younger firms also remains constant. Analogues in the natural sciences include viruses and bacteria, which undergo many types of equilibria during the average human life span. Within forest ecosystems, the relationships 
the macro-evolution of historical regimes from agent-level equilibria among the system's constituent parts.

This flies in the face of the current emphasis of agent-level equilibria in mainstream economic analysis. Today the political economy of institutions enjoys a central position in the study of large-scale political, economic, and social change; and with the concept of institutions as equilibria, it joins the mainstream of economic analysis. ${ }^{4}$ In more general work in economics, a 'model' usually implies a search for equilibrium, a point of balance, a condition of rest, a state of the system toward which the model depicts convergence over time. An economy is either at equilibrium (or one of its equilibrium positions) or is movingand probably moving rapidly-toward an equilibrium. ${ }^{5}$ That position presumes three basic properties: the consistent behavior of the agents; stability, which is the outcome of some dynamic process; and the lack of incentives for agents to change their behavior or coalitional structure once an equilibrium is attained.

Pointing to the shifting consensus in favor of the institutions as equilibria approach, institutional economists Avner Greif and Christopher Kingston remark that 'a growing body of recent research on institutions places a theory of motivation at the center of the analysis, and thereby endogenizes the 'enforcement of the rules.'... This perspective focuses on how interactions among purposeful agents create the structure that gives each of them the motivation to act in a manner perpetuating this structure ...' (Greif and Kingston, 2011).

The concept of institutions as equilibria does enable us to see how individuals, acting in self-interested ways and according to environmental constraints, create, evolve, and enforce rules (institutions as rules) to transact business and engage productively. Over time, as rules become formalized, and as penalties are prescribed to punish deviations, these interactions lead to an overall social equilibrium in which it becomes in everyone's self-interest to adhere to the institutional setups (the rules of the game). The result, according to this approach,

between foxes and rabbits can undergo a great number of different reproductive cycles in the forest's life span.

4 In economic historian Douglass North's original proposition, institutions are 'the humanly devised constraints that shape human interaction' and the 'rules of the game' (North, 1990: 3). This insight led early work in new institutional economics to focus on exogenous constraints (or exogenously given rational choice 'game forms'). But it has become apparent that institutions as rules of the game cannot, by themselves nor through decree, constrain behavior. North's institutions as rules thesis did not apply the concept of equilibrium, although it was implicit in his rules of the game. The concept of institutions as equilibria of strategic games, in which rule-based institutions are the mechanisms by which people are incentivized to follow certain behaviors and practices, is a natural correlate to the original proposition. According to the expanded theory, a 'regularity of behavior' is the endogenous motivator that creates and sustains an institution (North, 2005).

5 For example, to understand economic growth, economists seek an equilibrium in which an economy's capital stock per worker, its level of real gross domestic product (GDP) per worker, and its efficiency of labor grow at the same proportional rate. Once the capital-output ratio is equal to its balanced-growth equilibrium value, the economy is on its balanced-growth path. 
is an agent-level equilibrium that translates to an overall systemic equilibrium formalized as an institutional setup, or pact, such as the laws enacted by Parliament or Congress, contract enforcement mechanisms to conduct trade, and electoral systems. From this overall equilibrium, derived from agent-level interactions, we are said to be able to observe a system-level stability. ${ }^{6}$

A few works on dynastic succession, in fact, employ models that imply a search for equilibrium. A notable example is a study by de Mesquita (2000), 'Popes, Kings, and Endogenous Institutions: The Concordat of Worms and the Origins of Sovereignty'. He demonstrates that the resolution of the Investiture Controversy (a power struggle between the papacy and monarchy) created a changed strategic environment with multiple equilibria. On the one hand, it induced kings to promote economic growth to gain control over the papacy; on the other hand, it induced the Church to invent new institutions to stymie economic growth in order to maintain its political centrality. As kings won this struggle over time, the papacy's primacy in determining dynastic succession gradually collapsed in favor first of monarchy and then, gradually, in favor of more democratic politics. Thus, macro-level change is explained in a micro-level equilibrium environment.

In de Mesquita and Smith's (2009) account, endogenous institutional change, produced by threats of revolution and coups d'état, is the micro-level mechanism yielding macro-level change. This approach is exemplary in the use of the mechanics of equilibrium analysis at the agent level to examine a complex historical phenomenon. Yet, it does not reveal how policy selection and agent dynamics correlate to ongoing change processes at the macro-level. Were the agent-level strategies the actual reflections of unalterable systemlevel constraints? The analysis that follows demonstrates the network linkages between multiple system levels.

Another argument of this paper is that revolutionary challenges are unlikely to succeed unless they penetrate the macro-environment. Thus, efforts in Europe to establish a republic, for example, by the Dutch in the late 16th century and later by revolutionary France in the 18th century, were short-lived and suffered numerous reversals after incurring the strong opposition of neighboring monarchs. ${ }^{7}$ Republics could not survive without changes in the macro-structure of power in Europe.

6 Hindriks and Guala (2015) call for combining both approaches in one framework, noting that the regularities of behavior to which all members of society agree are difficult to separate from the rules, and that it is unrealistic to say that the rules are redundant and that only actions matter. A rules-in-equilibria account, they insist, is preferable to either the institutions as rules or the institutions as equilibria conception because it recognizes that institutions help players reach coordination and economize on cognitive effort.

7 The Republic of the Seven United Provinces (1581-1795) was connected to the system of royalty via an elected Stadholder from the House of Orange. The Dutch exited the Europe-wide system of royalty after revolting (1568-1648) against the Roman Catholic Philip II of Spain, their lawful, hereditary ruler. The revolt led to the formation of the Dutch Republic (United Provinces), one of the first European 
Napoleon grasped this idea, which is why he invaded Russia and risked losing most of his army in 1812. He understood, in the language of his day, that the command structure of Europe resided in its networks of royal families and that they functioned as hubs, with connections to subordinate members across the entire continent. Napoleon believed that the only way to preserve the fundamental values of the French Revolution was to destroy the hubs of the old structure, and to create a new structure, establishing himself as the central hub. His fear was that even if a few hubs of the old distributed system remained, they could restore the deleted hubs, putting the revolution in jeopardy. (Had Napoleon succeeded, he would have established a network governed, as we shall see, like China's. $)^{8}$

Napoleon was proved correct by the events that followed his defeat. A reactionary Russia under Czar Nicholas I became the gendarme of 19th-century Europe, eventually helping the Austrians defeat the Hungarian uprising in 1848. The Czar's own empire was predominantly Slavic, but he identified his interests with the fortunes of a fellow monarch, not with the people he ruled. The failure of Europe's 1848 revolutions illustrates that revolutionary pacts in particular states are unlikely to survive unless they alter the network structure's macro-logic.

One of the principal analytical advantages of a systems approach is that it allows one to distinguish macro-level properties, some of which are neither discernable from the properties of the system's agents nor reducible to the behavior of these agents. As we will discuss, resilience is one such macro-level property. Chandler (2014) and Holling (1973) argue that stability is another, and illustrate that there are trade-offs between stability and resilience-although over the time frames discussed, these trade-offs are not even knowable by the agents, as they involve eras and epochs that far exceeded the lives of individual agents. We will discuss these two properties, and their respective trade-offs and advantages, in section Resilience and stability trade-offs in China and Europe.

\section{Identifying hypernetworks in Europe and China}

This paper proposes to correct the idea that agent-level equilibria can aggregate to create equilibria at the macro-level. It argues as well that disequilibria at agent levels-seen in shifting borders, revolutionary pacts, codes of ethics, the rise and fall of royal houses, and other actions and interactions occurring within that complex system-do not necessarily aggregate into a pattern of stationarity at the macro-level. Despite fluctuations within a particular nation state or states, the properties of resilience and stability that reside in the hypernetwork can

republics of the modern era. The Staten-Generaal tried without success to find a suitable royal Protestant protector; the United Provinces finally resolved on electing a titular leader. In 1806, the Netherlands reverted and became a constitutional monarchy.

8 de Tocqueville (1955) remarks that French economists of the late 18th century admired China's centralized political structure and governance by a meritocratic civil service. 
remain unchanged. Like the backcloth of an opera, the hypernetwork remains stationary, largely unaffected by the drama onstage,

A focus on the nation state as the level of analysis will not reveal the key institutional determinants that account for the longevity of Europe and China relative to other historical regimes. European dynasties came and went, and any part of Europe was subject to invasion by any other part. Yet Europe's hypernetwork structure, of interconnected royal families, provided continuity across the continent that transcended the nation states. Its connectivity would break apart only with the removal of all the hubs. In China, as well, dynasties rose and were toppled, and their collapse brought periods of chaos; yet, the hypernetwork structure reappeared time after time, in its familiar hub-and-spoke form.

\section{The hypernetwork structure and resilience: the European example}

The robustness of regime dynamics resides in the structure of the hypernetworkin the patterns of connectivity among the hubs of the system-rather than from a simple aggregation of agent-level equilibria (Johnson, 2013). As we will see, there were advantages and disadvantages in the network designs of China and Europe, as illustrated in their sociocultural evolution over many centuries. Europe's state resilience lay in the connected dynasties ruling across the continental 'fabric'. The aggregate hypernetwork structure that those dynasties formed kept Europe from transitioning into instability when abrupt shocks disabled a particular royal lineage. Even if a royal house fell, the remaining hubs would self-organize by 'rerouting the traffic' on the network. Thus, for example, the Royal House of Plantagenet, the Royal Houses of Tudor and Stuart, and the House of Hapsburg all became extinct, but dynastic rule persisted. Understanding this ability to reconfigure without system-level breakdown is essential for explaining the dynamics of Europe's long-term development trajectory.

Europe's cultural continuity thus resides in its small-world network connectivity, a hierarchy of many small nodes held together by a few larger hubs that are themselves connected to a small number of yet larger hubs. In such networks, if one hub is destroyed, the remaining nodes diffuse and reconnect to a neighbor. Links to a few highly connected hubs prevent the smaller nodes from falling into isolation. Thus, the behavior of the system, even under extreme stress, is not entirely random, lending resilience to the system as a whole.

Like the CEOs of large corporations, Europe's royal families bridged the various subunits to unify the many discrete functionalities. This network structure of decentralized yet interconnected hubs enabled Europe to adapt to a changing environment, survive disruptive events, and accommodate evolutionary changes across local systems.

Europe had experienced its first catastrophic breakdown after the highly centralized Roman Imperium broke apart in the 5th century. The end of the 
imperial system led to the evolution of a new form of government across the continent. Based on feudalism, it eventually gave rise to the consolidation of states into disparate sovereign units. No center remained; instead, the continent's dynamism shifted from one region to another. Regimes came and went, and advantage shifted from one royal house to another, without any one hub strong enough to secure a monopoly on victory. A shift of power from one dynastic lineage to another did not entail catastrophic, continent-wide demographic outcomes.

This kind of scale-free structure protected the system from random failure, and because the ecology they inhabited survived, Europe's interconnected monarchies remained intact as a governing class, exhibiting both continuity and change over a millennium. This small-world network of princely and royal houses governed continuously-and the hypernetwork generated by this system of dynastic succession maintained its stationarity, despite a wide spectrum of observed micro-equilibria at agent levels, where profound variations in outlook existed, technologies changed, and formal institutions came and went. An innovation by one dynasty was parried by a counterthrust from another. Although intermarried, the Hapsburgs, Bourbons, and Hohenzollerns continually competed to contain each other's ambitions. The smaller networks created by each hub were not necessarily highly stable, but the small-world network of the great families outlived these variations.

Moreover, what this kind of hypernetwork loses in stability, it gains in resilience, the capacity to accommodate and absorb great intermittent stresses. With its distributed, mesh-like 'architecture', enough redundancy exists to enable communication between remaining hubs, so that actions and ideas can spread 'horizontally'. Thus, even when intermittent and episodic transformations occur at the agent level, the macro-stability of the system is not disabled.

The composite and timeless representation of European dynastic marriages (see Figure 1) from the 14th to the 20th centuries helps explain why describing Europe solely in terms of decentralization gives short shrift to the patterns of hubbased communication that enable lateral communication across the network. The diagram depicts the organization of European dynastic marriages from the 12th to the 20th centuries as a scale-free network, in which a few highly connected hubs connect the smaller nodes with one another. With every node linked to every other through a hub, connectivity (and redundancy) expands explosively. For the system to collapse, all the central hubs must be destroyed, otherwise the traffic will reroute among the surviving hubs.

\section{The hypernetwork structure and stability: the Chinese example}

China's regime structure, with an emperor at the center of a hub-and-spoke structure of governance, produced a hypernetwork of a different kind; its strength resided in the great efficiency with which information circulated from one end of a far-flung empire to another. However, the hypernetwork structure also made 
Figure 1. The European network of dynastic marriages.

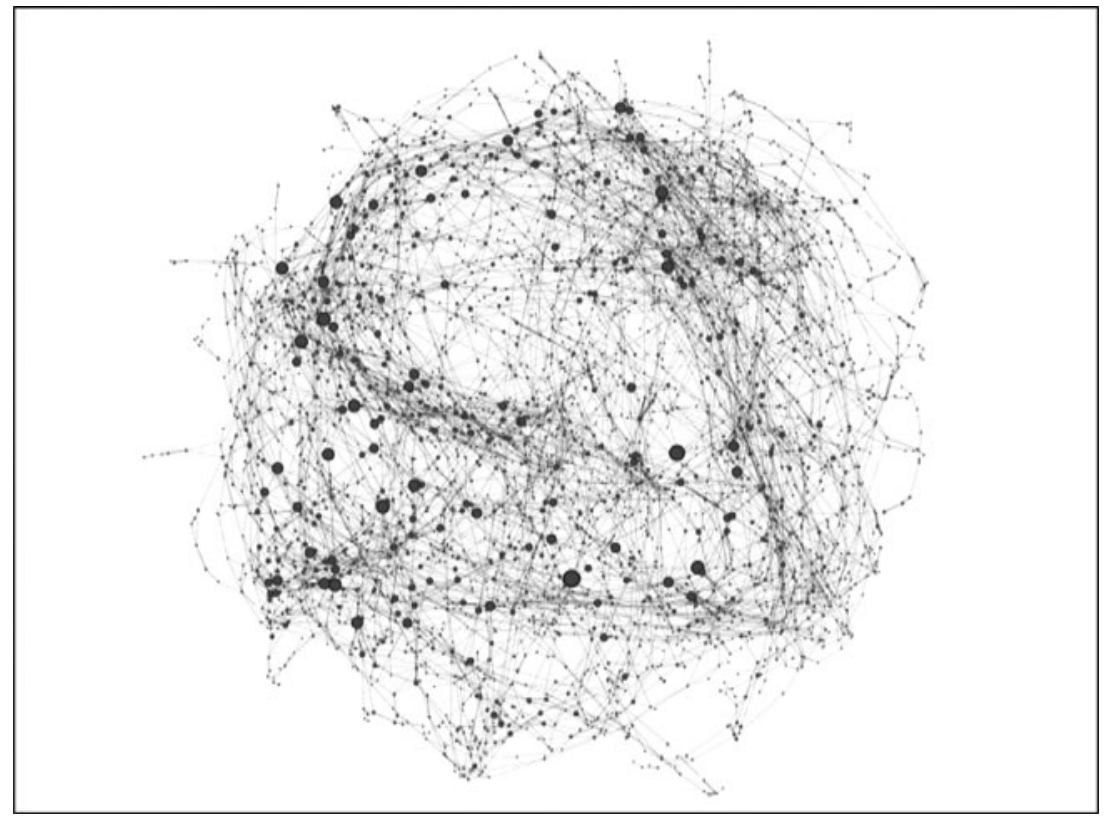

Source: DBpedia, using Gephi software (Comer and Palmer, 2012). Note: The timeless, scale-free character of the network shows 3,972 dynastic marriages beginning in the 12th century. The dynasties include royalty, as well as nobility, popes, bishops, and electors. Bishops and popes are expected to be celibate, but some had children for the express purpose of establishing alliances, and these are included. Node size is based on connectivity, determined by centrality and 'betweenness'. For an overview of these measures, a good source is Wikipedia.org/wiki/Centrality. Neither time nor nationality is taken into account. The diagram depicts the underlying graph structure of the network.

the state more vulnerable to massive shocks. In times of great disruption, only the links that were connected with other links could hold the empire together, and China had a few of these.

Dynastic collapse had extensive social and economic consequences, and the rebuilding process was exhaustive. Nevertheless, the institutions of China's dynastic system invariably reappeared. In this sense, the Chinese dynastic system exhibited stability rather than resilience. (Resilience depends on the redundancy of hubs, and China had just one central hub.) Yuri Pines explains that 'the peculiar historical trajectory of the Chinese empire is not its indestructability-it witnessed several spectacular collapses-but rather its repeated resurrection in more or less the same territory, and with a functional structure similar to that of the pre-turmoil period' (Pines, 2012: 3).

Ecologists Holling and Gunderson (2002: 25-62) establish a significant distinction between resilience and stability with applications to the institutional dynamics of complex systems. 'Resilience determines the persistence of relationships within a system', writes Holling, 'and is a measure of the ability 
of these systems to absorb changes in state variables, driving variables, and parameters, and still persist' (Holling, 1973: 17). In this sense, the hypernetwork resilience is a gauge of the maximum perturbation that a regime can withstand, and its capacity, afterward, to make adaptations that foster the next wave of transition. 'Stability, on the other hand, notes Holling, is the ability of a system to return to an equilibrium state after a temporary disturbance' (Holling, 1973: 17). ${ }^{9}$

The definition of resilience in common use by ecologists and others who study complex adaptive systems applies here. Resilience is the ability of the macro-system to absorb subsystem disturbances occurring, while retaining its own system of rules and procedures. However, resilience at the hypernetwork level also shapes the capacity of the micro-system, the regime. This stability made China similar to Europe at macro-levels—but even at the micro-levels, China experienced far less variation. What made the European system more resilient was that its hypernetwork survived dramatic local transitions intact.

\section{Resilience and stability trade-offs in China and Europe}

There were trade-offs between stability and resilience in both Europe's and China's hypernetworks. As noted previously, in the case of Europe, one such trade-off was redundancy, found both in the replication of communication channels among the multitudes of political jurisdictions, and in considerable institutional replication. The resilience of the state system generally resided in the adaptive capacity of its distributed network structure to survive drastic events. Yet, in a paradox of small-world network structure, Europe proved to be both highly unstable and highly resilient. ${ }^{10}$ This is because a decentralized network comprising many dense connections is difficult to manage, and thus may be prone to disruptive large events that could eliminate one or more hubs.

By contrast, China's hub-and-spoke system of rule exhibited great efficiency in maintaining communication and continuity among the government structures of a far-flung empire, which helps explain the recurrence of this system of rule by each successive dynasty. A study of social networks by Burt (1992) explains how centralized (hub-and-spoke) networks outperform decentralized networks. They support effective decision making, Burt argues, by strengthening the leadership's decision-making capacities. They provide greater opportunities for information access, timing, and monitoring, making management less costly in terms of energy, time, and resources.

In China, the hub-and-spoke system reduced the amount of time that information had to travel from the center to the provinces and back again. Fewer

9 Holling et al. (1995) refined the definition of resilience further, pointing to (1) the degree of the disturbance that can be absorbed before a state change occurs, and (2) the rate of recovery from a perturbation.

10 The implications for a system's aggregate resilience of small-world connectivity are discussed in Newman et al. (2006), Barabasi (2003), and Strogatz (2003). 
redundant contacts increased the efficient flow of information to the center and required less effort to maintain clusters of influence. Instead of maintaining relations with the entire network of spoke contacts, the central decision-maker could preserve resources to reward the primary contacts delegated to the task of maintaining the total network, and could utilize the conserved resources to expand the network to include new clusters of influence.

Whatever trade-offs arose between the properties of stability and resilience in Europe's and China's respective hypernetworks, they were ultimately made according to widely different adaptive values, i.e., according to the properties that most ensured the hypernetwork's perpetuation. Thus, redundancies in the European's scale-free network system absorbed considerable scarce resources but lent resilience. China utilized a far more efficient system of communication, but with the attendant risks of a central hub and its reliance on imperial bureaucracy.

In China, the dynasties themselves lasted generations, if not centuries. Yet should the throne fail, the 'transitions' were not peaceful. The disrupted communication channels would render the entire polity more susceptible to collapse; the remaining nodes, much like isolated islands, were unable to communicate. This made imperial China vulnerable to intervals of extreme disorder since subsidiary systems of governance had to be rebuilt and replaced.

Each dynasty's collapse disabled the center. Rebellion from within and invasion from without produced cycles of decay of long duration, in which the institutions of central rule retreated or disappeared entirely. During these transitions, the underlying economic and social situations of the population suffered on a massive scale. Nearly a century of intense warfare accompanied the transition from the Yuan to Ming dynasties (1350-1450). The fall of the Ming to the Qing dynasty spanned the period 1550-1683, with warfare continuing into the early 18 th century.

\section{The endurance of dynastic lordship in Europe}

The great instability of its particular regimes makes Europe seem weak and vulnerable to easy conquest; its intrastate governance seemed far less robust than China's. However, the small-world network structure of the aristocracy acted as the source of system-wide continuity. In such small-world networks, most of the components (nodes) are not themselves linked to many others. However, as we shall see, a small number of high-connectivity nodes link many of the nodes to any other, and to other high-degree nodes that derive their social power from the length of their connectivity to other high-degree nodes, rather than the extent of their connectivity to a larger number of smaller nodes.

\section{Europe as a small-world network}

The industrialization of Great Britain exemplifies the remarkable small-world continuity, balancing aristocratic entitlements with the ambitions of the rising 
industrial elites. Even after systems of production were transformed, no such equally dramatic events or clearly decisive changes to the social structure of authority occurred (Southern, 1953: 13). '[T]he aristocracy successfully maintained its power during all the vicissitudes of three-quarters of a millennium', notes historian Jack Hexter, 'during which almost everything else changed, quite drastically' (Hexter, 1961: 19). The knightly aristocracy, along with the monarchy, surrendered its primacy in Britain's social ordering only after World War II (Cannadine, 1999).

The evolution of royal families fanning out across Europe allowed for multiple connections among regions and systems, and serves as a prime example of hypernetwork activity. When World War I broke out in 1914, monarchs ruled most European states, and almost all the royals were related to one another in a kind of small-world network; Queen Victoria's direct descendants sat on the thrones of Britain, Denmark, Greece, Germany, Norway, Russia, and Spain, earning her the sobriquet 'Grandmother of Europe'. The social and economic effects of industrialization did not deter the crowned heads of Europe from consolidating their national powers and alliances. ${ }^{11}$

Of the major European nations, only France and Switzerland were outliers. Switzerland did not fight in World War I, and France entered the war as a republic. 'Except in France the kings remained the divinely ordained 'centerpieces' of Europe's authority systems', writes historian Arno Mayer in his magisterial study of the end of the old order in Europe (Mayer, 1981: 11). He notes that '[e]ven in France, where the ancient regime was pronounced legally dead between 1789 and 1793, it kept resurfacing violently and lived on in many ways for more than a century' (Mayer, 1981: 6). Four failed efforts to restore monarchical government occurred during the 19th century, and royalist sympathizers in France were abetted by supporters across the continent.

The collection of royal dynasties, spread out across Europe as a hypernetwork, shaped the territorial evolution of European states and gave order into the whole system. Describing the system as decentralized without considering the patterns of communication among the nodes of various sizes illuminates an incomplete framework. Yet most scholarship of European state building maintains primarily a national level, emphasizing competitive state-level fragmentation rather than a system-level focus.

\section{Intermarriages among noble bouses}

It is remarkable that during the late medieval period, circa 1500, Europe contained more than 500 distinct dominions-sovereign or quasi-sovereign jurisdictions that were largely independent political units. Yet, no matter how fragmented feudal Europe was to become, no town or village could ever legally

11 Victoria's importance in the network structure of European royalty comes from the fact that her ancestors, most notably King George III, were highly connected (Comer and Palmer, 2012). 
claim to be the subject of more than one kingdom. A testimony to the strength of the monarchical tradition is that although many independent powers arose, only to fall into decay, even at the peak of power, none ever dared to claim a royal title or to deny the bonds of fealty to a king. Despite the intensive selective pressures on European societies to compete by constantly updating their political, economic, and. military structures, at no time until Napoleon did a usurper ever claim the status of royalty. Marc Bloch underscores 'no great feudatory, however powerful he might be, ever dared to demand the most sacred part of the ceremony of being the 'lords anointed', a status found only among kings and priests' (Bloch, 2014: 400). The belief in the hereditary vocation of a dynasty over an individual prevailed, ensuring that when a king died, the kingdom remained.

The 8th-century Germanic kingdoms laid the basis of Western Europe's political evolution, which would establish the borders of both medieval and modern Europe. ${ }^{12}$ Bloch notes, 'thus the feudal era witnessed the emergence of the first lineaments of a political map of Europe. ... [It] also saw debated those problems of frontier zones which were destined till our own day to be responsible for the spilling of both ink and blood. ... [T] the most characteristic feature of this geography of kingdoms was that though their territorial limits were so fluctuating, their number varied remarkably little' (Bloch, 2014: 399).

This phenomenon found among the crowned heads of Europe-in which every royal house was connected in some way, if only remotely, to every other-is not merely a curiosity in the history of the continent. Via their elaborate protocols of intermarriage, the small-world hypernetwork that developed formed a strategic ecology and it lent stability to society, enabling state formation (Bloch, 2014: 155).

Over time, and in large measure due to the effort of the Church and its support of the combined practice of primogeniture and female inheritance, the various political entities and principalities were concentrated into the hands of a few royal families. The logic of dynastic succession was the primary driver of the territorial consolidation of these fragmented units. War was an instrument used to accelerate or decelerate the progress, but the big gains, such as the unification of France and Spain, were achieved through the logic of dynastic accumulation. ${ }^{13}$ The Germanic territories of the Holy Roman Empire adopted primogeniture later in the 18th century, and this was the reason they suffered

12 Bloch concludes, 'There could be no more eloquent testimony to the continued strength of the monarchic tradition, much older than feudalism and destined to survive it' than the fact that no vassal, no matter how powerful, ever rose to usurp the title of king (Bloch, 2014: 400).

13 For example, a continuous line through the Capetians (987-1328) and Valois, a cadet (younger son) branch of the Capetian dynasty (1328-1589) to the Bourbons, another cadet branch of the Capetians, that ruled until 1792, enabled French monarchs to unify France. Dynastic marriage was a principle means of Hapsburg aggrandizement between 1438 and 1740. The Habsburg monarchy of Charles V, of the 16th century, the largest political entity of its day, was largely the result of dynastic accumulation. The unification of the Low Countries was an accident of dynastic succession. The logic of dynastic 
continual fragmentation. Contrary to the often-repeated remark of sociologist Charles Tilly that 'war made states and states made war', the major states of Europe were born of dynastic accumulation. The map of modern Europe is roughly the product of dynastic marriage (Brenner et al., 2003). ${ }^{14}$

The legal framework of dynastic marriage was established with the blending of property rights and political power. The same laws, norms, and customs that governed the transmission of landed property also held and transmitted political power. This intertwining of public authority and property allowed for the orderly transmission of the office of the head of state from one generation to the next. Most important, these laws, behaviors, and customs transcended regional, sectarian, and political boundaries. They were prevalent throughout the European continent, extending from Britain to Russia.

The papacy played a central role in the cultural and ideological cohesion of Europe. In one sense, the hypernetwork formation of the papacy is much like the structure of imperial China, being the central hub of a hub-and-spoke system that controlled much of the political competition in Europe, including control of dynastic marriages. It held the essential power to anoint and therefore legitimize secular power, but it did not exercise that power in its own name. Nor did it control civil administration. The Chinese emperor played both roles; thus, as concentrator of authority, the Chinese throne far exceeded the power of the pope.

The Church hierarchy is best understood as a parallel hypernetwork within the larger European ecology. The Church's independent stature ensured that the right to justice became part of the value system of Western Europe, for the Church insisted that no king could deny the right to justice of even the humblest servant.

Neither Norbert Elias and nor Sharma use the term hypernetwork, but both nonetheless emphasize how royal marriages were the pivot upon which the European system of international relations rotated, and that 'each shift of power directly or indirectly involved every unit, every country' (Elias, 1983: 300). The higher-degree linkages and rivalries between royal houses propelled the formation and inter-relations among states-and the institution of dynastic succession, driven by the contingency of birth, marriage, and death in the leading princely families of Europe, determined the distribution of power in Europe' (Sharma, 2015: 169). Intermarriage was the prevailing means to secure, maintain, and extend power among reigning families from the medieval era until the outbreak of World War I.

accumulation was also behind the Austro-Hungarian monarchy (1867-1918) of the Habsburg dynasty, a multilingual, multicultural empire of more than 50 million inhabitants (Brenner et al., 2003).

14 Nathaniel Taylor observes, 'Ultimately ... in the wake of competition and economic pressure, aristocratic families abandoned co-lordship in favor of a vertical, dynastic structure of succession, restoring the indivisibility of lordship. ... The end result ... was a reorientation of post-Carolingian society under dynasties identified with regional power bases and led by a single (male) heir' (Taylor, 2005: 130). 


\section{European persistence: the paradox of maladaptive institutional resilience}

Dynastic succession is not a hypernetwork. It is an institution through which the hypernetwork of royal families perpetuated itself. The network of royal houses can be interpreted along three dimensions: first, a rule-based dimension (or house rules), albeit more customary than formal, which describes how dynastic property is to be transferred; second, an equilibria dimension, of strategic games created with self-reinforcing behavior; and third, a system of symbolic representation in which status is itself an institution, regulated by society's symbolic order.

Stable systems can generate unintended long-term consequences-feedback loops and path dependencies are often overlooked—but the resilience of a system can also be maladaptive. For example, although dynastic succession facilitated the territorial and administrative consolidation of continental Europe, it also incited continuous warfare.

'Consider the consequences if a system were highly resilient', note Holling and Gunderson (2002). 'Is that entirely a desired condition?' Remember, resilience in complex adaptive systems is the capacity to absorb and recover from perturbation; in the face of large disturbances, variables would shift and move, but the system would maintain its control and structures. In the case of Europe, the resilience of the monarchy as the source of political authority on the eve of the Great War jarred with the structure of a society changed by a century of increased regional and global industrialization and capitalism. The efforts to preserve dynastic lordship at the opening of the 20th century exemplify how the resilience of a particular social order can prevail without possessing a welfareenhancing property.

\section{The European ruling elite and the status-bestowing function of militarism}

When war broke out between Germany and Britain in 1914, Germany's Kaiser and Great Britain's King were not merely cousins, they were first cousins. Considering these shared genealogical connections among the princely dynasties of Europe, why was war unavoidable?

Although not the primary instrument toward territorial consolidation, war defined rank, title, and status, making prowess a foundation of legitimacy and stability. The military role of Europe's royal elite had a constitutive character, with its own rules and protocol. Prowess in the conduct of warfare assigned status, as well as functionality, to the traditional society of orders, with the monarchy's symbolic power as the source of justice and leader of the army. Thus, Josef Schumpeter in Imperialism and Capitalism explains that a perennial belligerence was instinctive for the monarchy. Imperialism developed on the continent because its heritage included a 'war machine, together with its sociopsychological aura and aggressive bent, and because a class oriented toward war maintained itself in a ruling position' (Schumpeter, 1951: 129). 
In Schumpeter's contextually rich understanding of European militarism, war and imperialism are embedded in the European state system because the legacy of prowess in warfare was how Europe's crowned cousins exerted their superiority over lineages of common stock and justified the honors of their office. Even when at war, they followed codes of honor to respect the esteem of their office, avoided taking each other hostage, and did not impose changes or dictate the internal institutional structures of a defeated rival.

Schumpeter's observations echo those of US President Woodrow Wilson, who posited the same explanation for the Europeans' perpetual tendency to be at war with each other and who further believed that this propensity would not end until the 'pretensions' of the elite genealogies that sustained it were 'checked and nullified' (Wilson, 1917).

Mayer, an admirer of Schumpeter, interprets the events leading up to World War I as efforts by European royalty to preempt their loss of status (Mayer, 1981). A militarist revival was under way, in which the Kaiser, the Austrian Hapsburgs, and Russia's Romanovs sought to form alliances to restore the Church and the army as the bastions of social order. The great families of Europe, Mayer speculates, feared class mobilization more than war; the latter, they imagined, would restore the natural hierarchy of society to their favor. At the risk of shedding a few royal thrones, the crowned heads of Europe envisioned a revival of the primordial values of the Old Regime and a remobilization of its civil and political institutions. ${ }^{15}$

\section{Europe's old regime in the context of the changed international system}

To explain the origin of the Great War, historians weigh the domestic issues of militarism and nationalism against external pressures, i.e., the system of alliances, war plans, the accumulation of crises prior to 1914. But to explain why a small perturbation like the assassination of Archduke Franz Ferdinand at Sarajevo on June 28, 1914, would have been enough to push the entire state system into a crisis, we do not need the deep, context-rich knowledge Meyer and Schumpeter bring to the subject.

If one considers only the way the European hypernetwork was structured, it is possible to construct a plausible explanation without a detailed understanding of the history. Network theory tells us that in a highly interconnected network of interrelated royal families, a small, localized event can trigger a cascade of military responses that sweep across national boundaries. In highly connected networks, what happens to some well-selected nodes can set off a wave of interactive responses.

15 Mayer (1981: 15) emphasizes a crisis of legitimacy that 'started the final act of the dissolution of Europe's Old Regime'. The precipitation occurred when 'between 1905 and 1914 the old elites proceeded to reaffirm and tighten their political hold in order to bolster their material, social, and cultural preeminence. In the process they intensified the domestic and international tensions that produced the Great War that started the final act of the dissolution of Europe's Old Regime' (15). 
Yet being prone to contagion does not explain why a small perturbation could have caused the sudden demise of the entire system. Another factor becomes paramount: The structure of the hypernetwork was transformed.

The peace repositioned the United States, transforming it into a principal hub of the system. From having been a peripheral player, the United States sought to redesign the system around a new strategy for global order premised on its preference for democratic universalism. America's role in peace transformed the landscape for those surviving royal houses because US foreign policy leaders challenged the constitutive and symbolic order of European society that supported militancy and imperialism.

Wilson was not content with merely redistributing the spoils of victory among the surviving lineages; he persuaded the allies to refuse to negotiate with any German government that had ties to the monarchy or the army. ${ }^{16}$ He insisted that new nations, carved out of the fallen empires of Turkey, Germany, AustriaHungary, and Russia, were to be representative democracies. This demand to reframe the basis of regime legitimacy clashed with Westphalian ideals that recognized the primacy of sovereignty. The peace redefined the basis of regime legitimacy in terms of the universality of democratic values and aspirations.

The subsequent congressional failure to ratify the League of Nations treaty and the country's retreat into isolationism contributed to the inability to institutionalize the Wilsonian ideal of a liberal world order. Instead of strengthening international law and organization under the auspices of liberal institutions, the victors at the Paris Peace Conference had self-interests that had less to do with Wilsonian ideals than with ensuring their own interests. With the unilateral abdication of Kaiser Wilhelm II, Germany's hub of social organization gone, and a decapitated German nation descended into lawlessness that spread across Europe. Another world war ensued before Europe's full integration into the liberal world order.

One might debate Wilson's role, but this essay is not the place. The key insight from the persistence of Europe's royal Old Regime elites and values before World War I, and their sudden disappearance after the war, is that national institutions and elite social behaviors are embedded in a much larger environment and do not exist in isolation from it.

As noted, when the 20th century began, only France and Switzerland, and the short-lived San Marco, were republics. Yet within a single generation, in both China and Europe, dynastic succession ceased to be the institution underpinning the orderly transmission of power. By the end of World War II, the surviving royal

16 Henry Kissinger explains, 'Wilson proclaimed that America had intervened not to restore the European balance of power but to 'make the world safe for democracy'-in other words, to base world order on the compatibility of domestic institutions reflecting the American example. Though this concept ran counter to their tradition, Europe's leaders accepted it as the price of America's entry into the war' (Kissinger, 2014: 256). 
houses of Belgium, Denmark, Luxembourg, the Netherlands, Spain, Sweden, Norway, and the United Kingdom were vestiges of their former selves. In China, the postwar restoration of central power spanned several decades, during which its people experienced warlords, a nationalist revolution, and eight years of Japanese invasion, followed by four years of civil war.

Despite their important respective strengths and vulnerabilities, the demise and re-formation of the hypernetwork of both systems in the early 20th century came from changes in the structure of the global network caused by the changing relationships among the principal hubs that created new sets of interconnections within the international system.

\section{Network design and the fate of Chinese dynasties}

A rich literature treats the emergence of China's authoritarian state institutions as being endogenous to an array of fundamental a priori geographic and ecological conditions. One well-known theory relates the origins of the centralized state to the need for drainage and irrigation. The constant need for unity to defend against nomadic invaders is also cited as an incentive to construct a state system capable of large-scale coordinated efforts. This essay is not the place to discuss these important debates. It takes the centralized state pattern as a given, and seeks to derive the implications of differences in network assemblage for China's socio-cultural evolution.

\section{China as a hub-and-spoke network}

The longevity of China's dynasties is one of the wonders of history. So too is the continuity of Chinese culture. The continuous feedback between culture and institutional structure is the subject of a sophisticated literature that combines the insights of sociologists, economists, and historians. Insights from network theory allow us to explore new possibilities for understanding this puzzle.

China, like Europe, entered the 20th century with its ancient protocols of dynastic succession the pivot of social order; but the administrative continuum that carried China through the centuries was a structural apex, with a single dynasty at the top, supported by an imperial bureaucracy as the mechanism of coordination and national integration. The combination of a meritocratic officialdom and a standing army under civil authority, writes Sidney Finer in The History of Government, distinguishes China's palace-style governance from that of other empires in recorded history (Finer, 1999: 756).

The Roman imperial traditions were never to be reconstituted in Europe, but in China, the Han dynasty (206 BC-221 AD) became the prototype of all subsequent regimes. The Han dynasty introduced an imperial university for official appointees in $124 \mathrm{BC}$; by $1 \mathrm{AD}$, official scholars began to administer examinations for entrants to government service, and justice was vested in organs of the central administration rather than local judiciaries. After 350 
years of division and disorder that followed the Han dynasty's collapse, the Tang dynasty (618-907) reconstituted what the Han had initiated, strengthening many of the characteristic institutions, notably the central officialdom that enabled the subordination of the military to civil leadership. The civil service system attained its pinnacle under the Sung dynasty (979-1279), which perfected the examination system developed during the Tang. As a further refinement of rule by officialdom, the Sung prohibited relatives of officials to conduct business with one another, and relatives of the empress or other imperial consorts were barred from becoming high-ranking officials.

The protocols of dynastic succession also took definitive form during Sung rule and persisted until the downfall of the imperial system in $1912 .{ }^{17}$ In earlier periods, usurpation of the throne by generals, empresses, and even civil officials was common, but as Reischauer and Fairbank (1958) note, never again after 960, when the Sung instituted the system of dynastic succession. ${ }^{18}$ Dynasties might fall by invasion, and members of the royal family could murder each other, but a 'non-royal' usurper could never again could capture the imperial throne.

In China, the hub-and-spoke system, with its reliance on imperial bureaucracy, continued to reappear. Even after prolonged and violent transitions, each successive dynasty rediscovered in the Confucian officialdom a means to integrate the bureaucracy and restore stability, establish the homogeneity of values, and ensure that officialdom, not privately accumulated wealth or military prowess, was the channel for social mobility. Ruling dynasties that failed to adopt it, such as the Mongol-led Yuan (1271-1368), which deviated toward a more explicitly tribal order, were relatively short-lived. The Ming (1368-1662) and the Qing (1662-1911) dynasties reverted to and strengthened officialdom.

\section{China's cycles of decay and renewal}

Chinese history is often told as a sequence of dynastic cycles of decay and renewal. Popular accounts carry a moral lesson: Successive dynasties rose from the ashes of

17 The social rank of the emperors' consorts was less a matter of state policy in China than in Europe, and instances when royal marriage was important for foreign policy, war, or diplomacy were far less prevalent. When intermarriages with royalty occurred, they were with families from outside China, in sharp contrast with the European tradition, where matches with lines from beyond Europe were rare. These interstate marriages, such as between France and Spain, Scotland and France, Britain and the Kingdom of Hanover, might have been considered foreign by the local population, but they were not 'beyond Europe'. When stability existed within the Chinese empire, marriages outside the empire were unlikely.

18 The royal dynasties that dominated the European stage until the early 20th century trace their origins to the Germanic kingdoms of the Early Middle Ages. 'The Sung had devised so stable a political system that Chao K'uangyin's usurpation was to prove to be the last in Chinese history. In early periods, emperors had repeatedly been robbed off the throne by their great generals, empresses, or civil officials. After 960, this never happened again. Dynasties continued to be snuffed out by foreign conquest or by popular revolution, and members of the imperial family stole the throne from one another, but no subject ever succeeded in usurping the imperial prerogative' (Reischauer and Fairbank, 1958: 203). 
their predecessors to attain peaks of cultural and engineering excellence, followed by corruption, factional quarrels, blind ambition, and moral decay that caused them to lose the Mandate of Heaven. A period of disorder results, and the Mandate of Heaven descends to a new dynasty.

More sophisticated accounts of Chinese history do not reject the idea of dynastic cyclicality but add an assessment of attendant economic and administrative failings. Reischauer and Fairbank (1958: 117-118) explain that at the upper bounds, where affluent central governments engaged in costly projects-palaces, roads, canals, and walls-the nobility and bureaucracy prospered and grew in numbers. Defending the larger empire also became costlier. The peasant farmers supported elites who paid a few taxes, causing expenditures to increase against declining revenues.

Revenue from the land tax, the chief source of government revenue, became progressively smaller over time as land was increasingly shielded from taxation by various means of falsification (Fairbank, 1948: 96). The peasants were left to bear a heavier burden triggering endemic revolts often led by fanatical religious leadership; lower-level resistance multiplied, despite efforts from the center at repression. Eventually, frontier defenses crumbled, armies defected, and the center weakened and collapsed.

The disorder that resulted from each breakdown set the empire back to a prior level of social complexity. Finer describes how the demise of the Han dynasty in 220 ushered in 350 years of disunion. Order was reconstituted by the Tang dynasty, which itself lasted some 300 years (618-907), only to collapse like the Han dynasty (Finer, 1999: 744).

Like many scholars of Chinese history, Finer observes that 'the collapse of each of the great imperial structures ushered in similar dismal periods of disunion, carnage, warlordism, and court dissension, followed by the predictable barbarian invasion and conquest' (744). The violence of the Ming dynastic transition spanned a century (1350-1450). The chaos caused by the Manchu conquest and defeat of the Ming that erupted in 1610 continued until 1683 and cost an estimated eighty million deaths. The wars associated with dynastic succession were of a length and intensity that had no parallel in the dynastic wars in Europe.

China's dynastic transitions can be observed in its nationwide demographic patterns, which follow political variability. Population numbers blossomed during the Sung dynasty (979-1279), only to decline dramatically to about half of its peak during the Sung collapse and Mongol conquest. The numbers did not recover during the Yuan (1271-1368), which coincided with the Black Death. Population numbers reached a new peak during the Ming period, increasing threefold over the 1291 level. Again, a drastic decline occurred when the Ming collapsed and the violent Qing conquest overtook it.

$\mathrm{Xu}$ et al. conclude that Western European population patterns are more consistent, that 'we see a much more gradual growth, only once interrupted between 1300 and 1400-by the Black Death. ... Steep declines in Chinese 
population levels are linked to transitions from one dynasty to another. ... Comparable declines in European populations did occur-during the Thirty Years War (1618-1648), for example, large parts of Germany and Poland were depopulated-but on a much more limited scale, due to the smaller size of European political entities. ... In China warfare was ... linked to changes in dynasties, but it seems to have had much greater consequences for the demographic development of the region' (Xu et al., 2015: 6). Although Europe's population trends exhibit primarily ecological or biological Malthusian dynamics-rather than political dynamics as in China-its economic and social development was able to travel further from its starting point than did China's.

\section{Stability and replication of dynastic China}

Identification of the properties that reside in the hypernetwork-and of the tradeoffs between stability and resilience-can help to describe one the peculiarities of the trajectory of Chinese history: the entire hub-and-spoke system of governance was 'resurrected in more or less the same territory and with a functional structure similar to that of the preturmoil period' (Pines, 2012: 3). Institutional replication occurred even when the new dynasty was a led by a foreigner.

Why was there such persistent reversion to the same system, with its authoritative bureaucracy, articulated social hierarchy, and an uninterrupted educational curriculum, despite, as Pines (2012: 2) writes, the 'tremendous changes in demography and topography, in ethnic composition of the ruling elites and socioeconomic structure, in religion and means of artistic expressions'? China scholars offer many answers. A widely accepted explanation places the question in its sociological context and emphasizes the emperor's need to weaken clan loyalties; the essential role of officialdom established governance via an impersonal institutional form. The exam system that permitted entry into mandarinate inculcated loyalty to the prince as supreme within the state. A meritocracy was more likely be loyal than were the landed gentry.

A centralized officialdom also enabled the emperors to maintain, provision, and conscript a standing professional army. Rather than depend on a nobility with an independent landed base in the form of fiefs (as was the case in Europe), the Chinese emperor, through his government, used conscription as the predominate means of recruitment. This further established the supremacy of the emperor, diverting local loyalty from local clans to the state.

The endurance of Chinese culture (in its broadest definition) and the limited value it allocates toward defending political freedom are puzzles that continue to intrigue China scholars. Is the tenacity of Chinese culture what predisposed generations of Chinese to restore the imperial order with similar governing structures? China's cultural and linguistic continuity survived invasions, such as the Mongols and the Manchus. Did this endurance makes the imperial order seem to be the 'normal and normative way of sociopolitical conduct', as Pines argues (2012: 3)? Does political culture have a self-organizing capacity? If so, 
what are the mechanisms of its persistence? Which comes first, culture or political institutions?

The concept of path dependency offers a way to answer this question and to think about the seemingly irreversible Chinese cultural forbearance of authoritarian rule. In complex systems, initial conditions matter. Once a network succumbs to a common state of dependence on a central authority, no successor form of that network will develop the capacity to administer itself. Once the component parts grow sufficiently isolated through estrangement from one another, they lose the capacity to act in concert-until a unifying agent steps in. Thus, De Tocqueville in the Old Regime and the Revolution concludes that it is 'far easier to estrange than to reunite a social order reduced to the status of isolated units' (De Tocqueville, 1955: 97-107).

This assessment of network dynamics makes it possible to go further than traditional perspectives and to advance the claim that Europe's network design made it far more capable of emergent complex behavior than China's. Even in the absence of a central or exogenous coordinator or control agent, Europe could undertake ambitious leaps in the development of new social structures and activities. Due to mesh-like network structure of the system, interactions among nearest neighbors could extend across the shared connectors and the wider system. Thus, all members of the system could influence one another without having to share information passed through a single unifying center.

The ease of organizing lateral communication may have been a longterm contributor to Europe's economic take-off. Co-evolutionary change that produced the Renaissance, the Reformation, the Enlightenment, and the Industrial Revolution could start in one part of Europe and attain continentwide significance. Such events altered the traffic flow, eliminating some nodes while adding others; nevertheless, the surviving hubs could self-organize and reconstruct the system. The greater resilience of Europe's hypernetwork enabled local institutions of governance, of technology diffusion, and ideological adaptation to evolve far beyond their starting points. This is the conclusion that network theory permits us to draw for the Great Divergence. ${ }^{19}$

19 The conventional view attributes Europe's dynamism to the amplifying effects of interstate competition that accelerated the development and articulation of states whose own intrinsic capabilities were well matched to their intrinsic conditions. Marc Bloch argues in Feudal Society that political fragmentation constrained centralizing monarchs from exercising personal absolutism; because merchants had options for exit, monarchs were prevented from gaining confiscatory powers over the property rights of their subjects (Bloch, 2014: 431). Greif and Tabellini (2010) write that by 1350, Europe's political fragmentation enabled cities to gain self-governance, which facilitated the building of institutions where contractual obligations were enforced via impersonal mechanisms. In 'Why Europe and the West? Why Not China?', economic historian Landes (2006) writes that political fragmentation and national rivalries compelled Europe's rulers to pay heed to their citizens, recognize their rights, and promote economic development. By contrast, institutions of imperial China revolved around a unitary regime and state control. This promoted stability and prevented economic and institutional reforms that could have threatened the status quo. 


\section{Social systems as multilevel systems: policy implications for the study of regime transition}

Both imperial China and a Europe ruled by interconnected royal houses were the longest continuous political systems in history. They shared a common remedy to the dilemma of orderly succession that had been a terminal weakness of historical regimes. Yet after enduring more than a millennium, both systems vanished during the same decade of the early 20th century. Differences in their respective hypernetworks account for important later differences in the evolution of China and Europe, up to and including the brutal collapse of dynastic lordship in the period surrounding World War I.

Systems of dynastic succession comprise many entangled subsystems. Interdependent bottom-up and top-down dynamics of components shape a system's long-term development. These dynamics cannot be identified in isolation. The top nodes are but one part of the network and by themselves do not propel the dynamics of the total network. Familiarity with a system's evolution at the macro-level will not enable predictions about its probable future state. However, observation of that evolution enables us to offer several generalizations for reflection. Historical regimes are likely to be gradual in formation, but sudden in their demise. The source of new structures at the macroscopic level may be hidden in microscopic details. Change at macro-levels is likely to spread across micro-levels and involve large-scale reorganization at those levels.

Regimes of dynastic succession of Europe and China have a macro-structure that is distinct from the micro-levels. Thus, even if a subdivision of the whole is subjected to intense observation, the details of the system's parts will not reveal the properties of the whole. Applying the laws that obtain lower levels will not allow us to reconstruct the hypernetwork level. This also implies that no fundamental level of description exists from which to derive social laws or 'enduring qualities'.

Our current knowledge of network structure does not enable us to make deterministic conclusions about the role of time in the evolution of dynastic regimes, and how time might determine the number of top nodes a system contains. Path dependency seems prevalent, making it difficult to establish a system with multiple nodes once there are a limited number of rulers. Likewise, when a system is populated by multiple monarchs, removing one endangers the

In How the West Grew Rich, Rosenberg and Birdzell (1985) claim that the West drew its advantage from institutional arrangements that diffused political power and authority, and which were economically more efficient than the alternatives. In The Lever of Riches: Technological Creativity and Economic Progress, Mokyr (1990) agrees that by fostering political competition between units, political fragmentation created incentives for Europe's technological progress (238). In contrast, he claims, China's reactionary bureaucracy viewed innovators as troublemakers (231). Other prominent scholars reliant on the 'competitive state system $v$ s. unified imperium paradigm' include Weber (1927), Diamond (2005), Parker (1996, 2008), and Wallerstein (2004). 
others. Hence, they all work together to ensure that no single dynasty gains a privileged position by rising above all the others. But once a centralized huband-spoke system is constructed, the nodes at lower level are no longer obliged to maintain contact and become unable to join forces should the need arise.

Although we are still far from establishing the rules that determine a shift from one institutional regime to another, this assessment of dynastic lordship, from a complex systems perspective, allows us to offer an insight about the world of social network architecture that has been relatively unexplored: The manner of assemblage of various network structures enables spontaneous development of complex behaviors, with important consequences for social evolution.

In conclusion, no scientific consensus exists on the correct of way of combining the dynamics at the various levels. 'Arguably, the need for a formalism to represent multilevel dynamics is this century's greatest obstacle to scientific progress', notes mathematician Johnson (2013: 178). ${ }^{20}$ This study shows that, viewed from a macroscopic perspective, a system can exhibit characteristics that differ from a microscopic perspective.

This paper has attempted to identify the organizational hierarchies that furnished institutional longevity to regimes in China and Europe over long time scales. It has considered how the trade-offs among dynamical processes of resilience or stability account for the endurance of those institutional regimes. Determining relevant system components, and how these components interact, is an intrinsically complex undertaking that calls for representing the multilevel dynamics in the evolution of social institutions. This in turns requires a better understanding of how local institutional adaptation is related to, and nested in, system-level variables.

Identifying the effects of emerging hypernetworks on policy outcomes is a critical step toward understanding clustering in the patterns of institutional adaptation among nations. It takes us closer toward finding the integrating logic or structure of their multilevel social systems.

\section{Acknowledgment}

Figure 1, The European network of dynastic marriages, is courtesy of Kevin Comer, a PhD candidate at George Mason University.

\section{References}

Andrade, T. (2016), The Gunpowder Age: China, Military Innovation, and the Rise of the West in the World History, Princeton: Princeton University Press.

Axtell, R. L. (2014), 'Beyond the Nash Program: Aggregate Steady-States Without AgentLevel Equilibria', Department of Computational Social Science, Krasnow Institute for Advanced Study, and Institute for New Economic Thinking (INET) Mathematical

20 Levin (1992) concurs, pattern and scale are the central problems for ecology. 
Institute and Oxford Martin School, Working Paper, Accessed December 18, 2016, http://www.css.gmu.edu/ axtell/Rob/Research/Pages/Agents_\&_Economics_files/ Beyond\%20the \%20Nash\%20Program\%20v1.1.pdf.

Axtell, R. (Forthcoming), Dynamics of Firms: Data, Theories and Agent-Based Models, Cambridge: MIT Press.

Barabasi, A.-L. (2003), Linked: How Everything Is Connected to Everything Else and What It Means for Business, Science, and Everyday Life, New York: Penguin Group.

Bloch, M. (2014), Feudal Society, Abingdon and New York: Routledge Press.

Brenner, N., B. Jessop, M. Jones and G. Macleod (2003), State/Space: A Reader', New York: Wiley-Blackwell.

de Mesquita, B. B. (2000), 'Popes, Kings, and Endogenous Institutions: The Concordat of Worms and the Origins of Sovereignty', International Studies Review, 2(2): 93-118.

de Mesquita, B. B. and A. Smith (2009), 'Political Survival and Endogenous Institutional Change', Comparative Political Studies, 42(2): 167-197.

Burt, R. S. (1992), Structural Holes: The Social Structure of Competition, Cambridge: Harvard University Press.

Cannadine, D. (1999), The Decline and Fall of the British Aristocracy, New York: Random House.

Chandler, D. (2014), Resilience: The Governance of Complexity, London: Routledge.

Comer, K. and M. Palmer (2012), 'A Network Analysis of European Royality', in Social Network Analysis, Krasnow Institute, George Mason University, Working Paper, Vol. 692.

De Tocqueville, A. (1955), The Old Regime and the French Revolution, S. Gilbert (ed.), New York: Anchor Books.

Diamond, J. (2005), Guns, Germs, and Steel: The Fates of Human Societies, New York: Norton.

Elias, N. (1983), The Court Society, Oxford: Oxford University Press.

Fairbank, J. K. (1948), United States and China, Cambridge, MA: Harvard University Press.

Finer, S. E. (1999), The History of Government from the Earliest Times: The Intermediate Ages, Oxford/New York: Oxford University Press.

Greif, A. and G. Tabellini, (2010), 'Cultural and Institutional Bifurcation: China and Europe Compared', American Economic Review, 100(2): 135-140.

Hexter, J. H. (1961), Reappraisals in History: New Views on History and Society in Early Modern Europe, New York: Harper Torchbooks.

Hindriks, F. and F. Guala, (2015), 'Institutions, Rules, and Equilibria: A Unified Theory', Journal of Institutional Economics, 11(3): 459-480.

Holling, C. S. (1973), 'Resilience and Stability of Ecological Systems', Annual Review of Ecology and Systematics, 4: 1-23.

Holling, C. S. and L. Gunderson, (2002), Panarchy: Understanding Transformations in Human and Natural Systems, Washington, DC: Island Press.

Johnson, J. (2013), Hypernetworks in the Science of Complex Systems, London: Imperial College Press.

Kissinger, H. (2014), World Order, New York: Penguin Press.

Landes, D. S. (2006), 'Why Europe and the West? Why Not China?', The Journal of Economic Perspectives, 20(2): 3-22.

Levin, S. (1992), 'The Problem of Pattern and Scale', Ecology, 73(6): 1943-1967.

Mayer, A. (1981), The Persistence of the Old Regime (1st ed.), New York: Pantheon Books. 
Mokyr, J. (1990), 'The Lever of Riches: Technological Creativity and Economic Progress, New York: Oxford University Press.

Newman, M., A.-L. Barabasi and D. Watts (2006), The Structure and Dynamics of Networks. Princeton Studies in Complexity, Princeton: Princeton University Press.

North, D. C. (1990), Institutions, Institutional Change and Economic Performance. Political Economy of Institutions and Decisions, New York: Cambridge University Press.

North, D. (2005), Understanding the Process of Economic Change, Princeton: Princeton University Press.

Parker, G. (1996), The Military Revolution: Military Innovation and the Rise of the West 1500-1800, Cambridge: Cambridge University Press.

Parker, G. (2008), The Cambridge Illustrated History of Warfare, Cambridge: Cambridge University Press.

Pines, Y. (2012), The Everlasting Empire: The Political Culture of Ancient China and It's Imperial Legacy, Princeton: Princeton University Press.

Reischauer, E. O. and J. K. Fairbank (1958), East Asia: The Great Tradition, Boston: Houghton Mifflin.

Rosenberg, N. and L. E. Birdzell (1986), How the West Grew Rich, New York: Basic Books.

Schumpeter, J. A. (1951), Imperialism and Social Classes, P. M. Sweezy (ed.), New York: Augustus M. Kelley, Inc.

Sharma, V. S. (2015), 'Kinship, Property, and Authority: European Territorial Consolidation Reconsidered', Politics \& Society, 43(2): 151-180.

Shepsle, K. A. (1979), 'Institutional Arrangements and Equilibrium in Multidimensional Voting Models', American Journal of Political Science, 23(1): 23-57.

Shepsle, K. A. (2005), 'Old Questions and New Answers about Institutions: The Riker Objection Revisited', in D.A. Wittman and B.R. Weingast (eds.), The Oxford Handbook of Political Economy, Oxford University Press, pp. 1031-1050.

Simon, H. (1962), 'The Architecture of Complexity', Proceedings of the American Philosophical Society, 106(6): 467-482.

Southern, R. W. (1953), The Making of the Middle Ages, New Haven: Yale University Press.

Strogatz, S. H. (2003), Sync: The Emerging Science of Spontaneous Order (1st ed.), New York: Hyperion.

Taylor, N. L. (2005), 'Inheritance of Power in the House of Guifred the Hairy: Contemporary Perspectives on the Formation of a Dynasty', in R. I. Berkhofer, A. Cooper and A. J. Kosto (eds.), The Experience of Power in Medieval Europe, 950-1350, Burlington: Ashgate, pp. 129-151.

Wallerstein, I. (2004), 'The Rise of State-System: Sovereign Nation-States, Colonies and the Interstate System', in World-Systems Analysis, Durham: Duke University Press, pp. 42-59.

Weber, M. (1927), General Economic History, London: Allen \& Unwin.

Wilson, W. Wilson's War Message to Congress, Pub. L. No. Doc. No. 5 (1917), United States: 65 th Congress, 1 st Session, Senate.

Xu, Y., B. van Leeuwen and J. L. van Zanden (2015), Urbanization in China, ca. 1100-1900, Utrecht University, Working Paper No. 0063. 